\title{
Novas práticas de governança da água? \\ O uso da pegada hídrica e a transformação das \\ relações entre o setor privado, organizações ambientais e agências internacionais de desenvolvimento
}

\section{Changing Water Governance Practices? Water Footprint Use and the New Arrangements among Private Sector, Environmental Organizations and International Development Agencies}

\author{
Vanessa Lucena EMPINOTTI* \\ Pedro Roberto JACOBI**
}

\begin{abstract}
RESUMO
Nos últimos cinco anos, em arenas internacionais, ocorreu uma mudança na percepção sobre o papel do setor privado no contexto da governança da água. Antes reconhecido como agente degradador do recurso, hoje é considerado por organizações multilaterais e ambientalistas como peça-chave na promoção da conservação da água. O objetivo deste artigo é entender como essa mudança de discurso redefiniu o entendimento da água de um insumo de produção para um indicador de responsabilidade socioambiental e como essa mudança se refletiu sobre o papel dos atores envolvidos nessa iniciativa. Para isso, o artigo analisa a apropriação do método da pegada hídrica pela SABMiller, empresa sul-africana produtora de bebidas, em parceria com a WWF e a GIZ. Ao utilizar o método da pegada hídrica para identificar a quantidade de água alocada nas atividades econômicas que ocorrem em bacias hidrográficas localizadas no Peru, África do Sul, Tanzânia e Ucrânia, a SABMiller iniciou um processo de reposicionamento no contexto político e dividiu a responsabilidade do uso eficiente do recurso hídrico com os outros atores da região. Além disso, organizações ambientais internacionais e agências de desenvolvimento se tornaram interlocutores da agenda industrial frente ao Estado e à sociedade, por se disporem a levar as propostas da SABMiller para esferas de tomada de decisão. Por fim, este novo arranjo criou oportunidades para a construção de novos espaços de negociação formais até então inexistentes.
\end{abstract}

Palavras-chave: governança da água; setor privado; pegada hídrica.

\footnotetext{
* Doutora em Geografia (Colorado University, USA). Pós-doutoranda do Programa de Pós-Graduação em Ciência Ambiental (PROCAM/IEE/USP). E-mail: empinotti@gmail.com

"* Doutor em Sociologia (USP). Professor Titular da Faculdade de Educação e do Programa de Pós Graduação em Ciência Ambiental da Universidade de São Paulo (PROCAM/IEE/USP). E-mail: prjacobi@usp.br
} 


\begin{abstract}
In the last five years, the private sector assumed a different position in the water governance context. Multilateral agencies and non-governmental organizations have recognized the private sector as one of the main partners in transforming and improving water quality, instead of just being water resources exploiter and polluter. This article aims to understand how the private sector moves in the decision-making arena redefining the water understandings from input to an indicator of socio-environmental responsibility, and at the same time starting to create new governance practices. To this end, it presents and discusses the empirical study of SABMiller, a world known beer industry, and its initiative in developing the $w a-$ ter footprint of its beer production in partnership with WWF and GIZ. When using the water footprint methodology to map water use in the industrial boundaries as well as the watershed, SABMiller also changed its position in the political sphere once the task for managing the water in responsible matters was shared in between the different actors of the region. Also, in this context, environmental organizations and development agencies became mediators of the industry's agenda with state and society since they assumed a position of bringing SABMiller's suggestions to the decision-making spheres. Finally, the partnership between SABMiller, WWF and GIZ created opportunities for new spaces of negotiation in the water governance practices, in which the industry could assume leadership positions until now mostly occupied by the State and civil society organizations.
\end{abstract}

Keywords: water governance; private sector; water footprint.

\section{Introdução}

Nos últimos cinco anos, agências multilaterais e organizações da sociedade civil de abrangência mundial começaram a identificar o setor privado não apenas como um agente consumidor e degradador dos recursos hídricos, mas também como um ator-chave na governança da água, capaz de promover o uso eficiente do recurso e sua conservação. Por outro lado, o aumento do risco nas atividades industriais devido à escassez de água em algumas regiões do mundo, combinado às altas expectativas dos consumidores e investidores com relação à responsabilidade socioambiental das indústrias, fez com que corporações voltassem a sua atenção às práticas de uso dos recursos hídricos (NATIONS, 2009).

Entre as estratégias utilizadas para diminuir os fatores de riscos externos, destacam-se as práticas que têm por objetivo promover o aumento da eficiência do uso da água nos processos produtivos, assim como reduzir o impacto negativo da atividade industrial sobre a qualidade da água presente em sua região de atuação. Com esse objetivo, empresas como Raisio, Lewis, Pepsi-Co, SABMiller e Unilever, em parceria com organizações ambientais, começaram a utilizar o método da pegada hídrica com a finalidade inicial de mostrar o seu impacto no meio ambiente e na disponibilidade de água, tanto na escala global como local.

A pegada hídrica representa o volume total anual de água utilizado na produção de um bem ou serviço consumido por um grupo de consumidores que incluem uma família, empresa, cidade, Estado ou nação (GERBENS-LEENES; HOEKSTRA, 2008). Em seu cálculo, o método considera não só o volume de água consumido a partir de diversas fontes, como a água superficial e subterrânea (água azul) e a água da chuva armazenada no solo (água verde), mas também a quantidade de água poluída durante o processo produtivo em um determinado local e período (água cinza) (HOEKSTRA, 2008b). Criado em 2002, o conceito de pegada hídrica se assemelha ao conceito da pegada ecológica - ao considerar a quantidade de água necessária na produção - e combina essa questão ao conceito de água virtual, que reconhece a presença da água como parte dos bens de consumo, assim como o seu fluxo internacional por meio de importações e exportações de produtos (REES, 1992; ALLAN, 1998).

A apropriação do conceito da pegada hídrica por empresas multinacionais, organizações não governamentais ambientalistas e redes de discussões internacionais como a GreenBiz.com, Water Stewardership Alliance e Water Footprint Network, transformou o setor industrial 
em um importante ator na modificação das relações entre os recursos hídricos e a cadeia produtiva e na promoção de novas relações entre as práticas de produção e o consumo da natureza. Onde antes o setor privado participava como prestador de serviço e tinha a distribuição da água como o seu principal negócio, agora também compreende empresas usuárias de água, onde o seu interesse é influenciar a governança da água por meio da discussão de práticas e parcerias que levem à valoração de tal recurso em seu produto final. Tal questão se torna relevante, principalmente nos países onde os espaços de negociação participativos e descentralizados não foram institucionalizados.

O objetivo deste artigo é analisar como o setor privado, em parceria com organizações não governamentais internacionais e agências de desenvolvimento, transformou a água de um insumo de produção para um indicador de responsabilidade socioambiental. Nessa nova realidade, o objetivo é entender qual foi o impacto dessa mudança sobre as novas alianças entre atores até então antagônicos, assim como o papel que cada um assumiu nas discussões referentes à gestão dos recursos hídricos em um ambiente onde os espaços de negociação formais entre o Estado, as organizações da sociedade civil e os usuários de água inexistem.

Com o objetivo de responder às questões levantadas acima, a parte empírica do artigo se concentrou na análise do desenvolvimento e apropriação do método da pegada hídrica pela empresa SABMiller em suas plantas localizadas na África do Sul, Ucrânia, Tanzânia e Peru resultantes de sua parceria com a organização não governamental ambientalista WWF-UK (World Wide Fund for Nature) e a GIZ, agência do governo alemão responsável por fomentar práticas que levam ao crescimento econômico de países em desenvolvimento. Para a coleta dos dados, foi utilizada uma combinação de métodos qualitativos que envolveram entrevistas semiestruturadas e a análise de documentos de arquivos.

Os dados foram coletados a partir da análise dos relatórios públicos, dos relatórios de sustentabilidade da empresa SABMiller e dos relatórios de atividades da WWF e da GIZ. Outra fonte de dados foram artigos de jornais e revistas, além de entrevistas com atores-chave na divulgação e elaboração da pegada hídrica que trabalham na WWF e na Water Footprint Network.
O material coletado foi posteriormente organizado em categorias que facilitaram a análise das informações e subsidiaram as discussões apresentadas nesse artigo.

\section{Entendendo a transformação da água a partir da perspectiva da Ecologia Política}

As interações que ocorrem no contexto da governança da água entre atores, instrumentos de gestão e políticas públicas são analisadas por diferentes perspectivas, que contribuem para o entendimento dessas questões a partir de prismas distintos. Neste artigo, a perspectiva de análise utilizada é a Ecologia Política, campo de estudo que surge a partir de trabalhos de geógrafos e antropólogos que analisam o uso e a transformação dos recursos naturais e dos processos ecológicos como consequência dos processos políticos e econômicos (PEET; WATTS, 1996; BRYANT; BAILEY, 1997; DEWALT, 1998; BRYANT, 1999). Nessa perspectiva, as relações entre sociedade e ambiente são observadas por meio dos processos de transformação da natureza em mercadorias, consideradas resultantes de práticas sociais capitalistas (CASTREE, 1995, 2003; HARVEY, 1996). Consequentemente, a natureza é transformada, assim como seus usos e entendimentos (PRUDHAM, 2003; BAKKER, 2004; SWYNGEDOUW, 2004).

Ao trazermos essa discussão para o contexto dos recursos hídricos, se entende que as alterações nas práticas de governança da água nos últimos anos foram consequência da transformação do recurso água em uma mercadoria resultante da apropriação de bens comuns por entes privados (HARVEY, 1996; ZIMMERER, 2000; PRUDHAM, 2003; BRAUN, 2008). Tal transformação trouxe uma série de mudanças nas práticas de governança da água, possibilitando aos pesquisadores identificarem novos arranjos institucionais, onde não só o Estado, mas também as organizações da sociedade civil e o setor produtivo se tornaram agentes de transformação nos processos de negociação (BAKKER, 2004; SWYNGEDOUW, 2004). Nesses novos arranjos institucionais, o setor privado se tornou um importante ator na definição de como os recursos hídricos são entendidos e valorados, a ponto de exercer influência sobre as práticas de governança e assim garantir seu acesso a tal recurso natural. 
Nesse contexto, a água contribuiu na transformação da paisagem econômica e social, por meio de suas relações com seres humanos, práticas econômicas e culturais que influenciaram na construção social dos recursos hídricos e seu impacto sobre as práticas de governança (SWYNGEDOUW, 1997, 1999; PRUDHAM, 2003).

Entretanto, é importante observar que, nos artigos citados acima, a relação entre o setor privado e a água teve seu foco na análise da participação desse setor no processo de privatização do sistema público de saneamento e abastecimento que ocorreu em vários países (PETRELLA, 2002; BAKKER, 2004; SWYNGEDOUW, 2006; JACOBI, 2009; LOTFUS, 2009), bem como no impacto das suas atividades na qualidade das fontes de água (LEONEL, 1998; WESCOAT; WHITE, 2003). No Brasil, essa discussão teve seu foco no entendimento de como este setor influenciou os processos de valoração da água e no desenvolvimento de instrumentos de gestão, como no caso da cobrança pelo uso da água (BRAGA; STRAUSS et al., 2005; FÉRES; REYNAUD, 2005; FÉRES, THOMAS et al., 2005; IORIS, 2007). Nestes casos, o recurso hídrico é considerado como um insumo de produção e é abordado como as práticas do setor privado impactam o acesso e a disponibilidade da água para outros grupos sociais e atividades econômicas.

Até o momento, pouco foi discutido sobre a atuação do setor privado sobre as práticas de governança da água no seu papel de usuário, pois o foco se concentrou em entender o setor privado em sua posição de provedor de serviço. Assumindo a perspectiva da indústria como usuária de água, torna-se necessário entender como a apropriação dos recursos hídricos nos processos produtivos influencia suas estratégias de tomada de decisão e negociação com os outros setores da sociedade, principalmente em países onde as instituições formais participativas não existem. Considera-se nisto o entendimento sobre como a utilização de indicadores de eficiência do uso da água pela indústria cria um novo valor para a água, não só econômico, mas também político. Tais questões irão contribuir para o entendimento das práticas de governança criadas e transformadas pelos atores sociais com o objetivo de garantir seu acesso à água.

\section{Governança da água, o setor privado e a pegada hídrica}

Nos últimos 30 anos, a questão da água esteve presente na agenda global ambiental, onde diferentes abordagens foram elaboradas e colocadas em prática (RIBEIRO, 2008). Entretanto, na década de 1990 aconteceu uma forte mudança na orientação em como os recursos hídricos deveriam ser manejados em decorrência da mudança do modelo de desenvolvimento internacional. Antes fortemente influenciado pelos princípios keynesianos - com o Estado como seu principal ator -, o novo modelo segue os princípios neoliberais que, influenciado pelo Consenso de Washington, assume o mercado como o principal protagonista (BANK, 1992; SIKKINK, 1997; SELIGSON; PASSÉ-SMITH, 1998; GORE, 2000; FINE, 2001). Com o objetivo de melhorar as práticas de uso e a eficiência da distribuição e do acesso à água, essa nova abordagem transformou a governança da água ao introduzir a privatização dos serviços de abastecimento e tratamento, ao adicionar um valor econômico ao recurso, ao criar mercados para a sua comercialização e ao introduzir práticas de tomada de decisão baseadas nos conceitos de descentralização e participação (BANK, 1992; LEE, 1995; LIPSCHUTZ, 1998; BRANNSTROM, 2004; BUDDS, 2004; JACOBI, 2004).

Enquanto as mudanças no processo de tomada de decisão foram bem aceitas e levaram à criação de um novo arcabouço institucional para o manejo dos recursos hídricos, como no caso brasileiro (JACOBI, 2006; ABERS, 2007; EMPINOTTI, 2007), na maioria dos países a reforma se limitou apenas à privatização dos serviços de distribuição, que foram recebidos com resistência, chegando a casos extremos - como em Cochabamba, na Bolívia, onde conflitos armados entre a população e a polícia ocorreram (BUSTAMANTE, 2004; GOLDMAN, 2005, PERREAULT, 2005). Com isso, a apropriação de princípios econômicos no manejo dos recursos hídricos não levou ao seu uso mais eficiente, como era o objetivo original de tais reformas.

Em resposta aos insucessos desta abordagem, agências multilaterais e governos começaram a se interessar por uma nova estratégia, desenvolvida principalmente 
em universidades holandesas e britânicas, que utiliza métodos baseados na contabilização do uso da água para definir práticas de governança que levem à maior eficiência no seu uso durante o processo produtivo. Nesta nova abordagem, dois conceitos se destacam: a água virtual e a pegada hídrica. O conceito de água virtual, criado em 1998, surgiu com o objetivo de desafiar a teoria que associa o estresse hídrico às guerras, mostrando a existência de outros mecanismos que regulam a oferta de água em um país, como, por exemplo, a importação de produtos agrícolas (ALLAN, 1998). Nesse sentido, a água virtual corresponde à quantidade de água utilizada na produção de um produto, abrindo dessa forma um novo diálogo sobre a mobilidade da água no planeta e tornando clara a ligação entre consumidores e produtores localizados em diferentes países (ALLAN, 2001, 2003). A partir dessa discussão, em 2002, surgiu o método da pegada hídrica, que tem como objetivo chamar a atenção para as dimensões globais da água por meio da relação entre o consumidor e as práticas de uso da água na produção de bens de consumo (HOEKSTRA, 2002, 2008a; HOEKSTRA; CHAPAGAIN, 2008).

$\mathrm{O}$ diferencial desse método consiste em várias questões, que vão desde a forma de contabilizar a pegada hídrica até a análise contextualizada de sua sustentabilidade que, por fim, traz a discussão para a escala de bacia hidrográfica e da necessidade de desenvolver práticas que envolvam os diferentes usuários locais. Com isso, $\mathrm{o}$ método é composto pelas fases de diagnóstico, contabilização do uso da água, avaliação da sustentabilidade do uso da água no contexto onde ela ocorre e recomendações de ações que levem ao uso mais eficiente do recurso hídrico (HOEKSTRA; CAPAGAIN et al., 2011).

A fase do diagnóstico compreende a definição do escopo e da escala de análise da pegada hídrica. A seguir, se inicia contabilização da água por meio do cálculo da pegada hídrica, que considera a pegada hídrica azul, a pegada hídrica verde e a pegada hídrica cinza. A pegada hídrica azul é definida como um indicador do volume de água superficial ou subterrânea alocada durante o processo produtivo. Para sua contabilização, é considerado o volume de água evaporado, o volume de água que não retorna ao corpo hídrico de origem e o volume de água que não retorna ao corpo hídrico de origem no mesmo período no qual foi captado (ex.: represas, armazena- mentos de água etc.). Já a pegada hídrica verde indica a quantidade de água de chuva alocada na produção agrícola e silvícola, referindo-se ao total da água liberada pela evapotranspiração das plantas, somada à água incorporada no produto final (HOEKSTRA et al., 2011). Por fim, a pegada hídrica cinza reflete a poluição da água que pode ser associada com a produção de um produto. Refere-se ao volume de água requerido para que a poluição de um processo possa ser assimilada pelo corpo de água, de acordo com o limite máximo estabelecido por legislação (ou qualquer outro limite adotado) ou em relação à qualidade natural do corpo hídrico em questão (HOEKSTRA et al., 2011).

A fase posterior à contabilidade é a de avaliação da sustentabilidade, onde a pegada hídrica é avaliada tanto por uma perspectiva ambiental como social e econômica. Esse exercício abre espaço para discussões que têm por objetivo definir as práticas mais adequadas para garantir a disponibilidade hídrica da região. Posteriormente, poderão ser estabelecidas ações, estratégias, planos ou políticas para soluções em relação aos resultados da pegada hídrica. Estas iniciativas incluem desde a otimização de processos, visando à redução da pegada hídrica, até a compensação - em uma mesma bacia hidrográfica - da pegada hídrica, quando não é possível sua redução (HOEKSTRA et al., 2011).

Alguns pesquisadores sugerem que os resultados da pegada hídrica deveriam apontar para uma revisão locacional de atividades produtivas, direcionando aquelas de uso mais intensivo para regiões de maior disponibilidade de água e vice-versa (HOEKSTRA; HUNG, 2005; HOEKSTRA; CHAPAGAIN, 2008). Tais práticas garantiriam a segurança hídrica das regiões, uma vez que os produtos seriam produzidos em áreas onde não ocorre escassez. Nesta perspectiva, as práticas de comércio exterior seriam impactadas, uma vez que a compra e a venda de produtos estariam atreladas à disponibilidade hídrica dos países de origem da produção.

Entretanto, tal perspectiva recebeu uma série de críticas que salientaram a importância de considerar não apenas a disponibilidade hídrica, mas também as características sociais e políticas da distribuição da atividade agrícola em diferentes partes do mundo (WARNER; JOHNSON, 2007; ROTH; WARNER, 2008; WICHELNS, 2010; BOELENS; VOS, 2012; EMPINOTTI; WARNER, 2012). Por um lado, 
observou-se que, nas práticas atuais de comércio exterior, os fatores que influenciam as estratégias comerciais estão baseados no crescimento econômico, na geração de emprego e na garantia da segurança alimentar e não na disponibilidade hídrica ou na sua escassez (VALLEJO; ROGERS, 2004; LOPEZ-GUNN; LLAMAS, 2008). Nesse contexto, o acesso à terra assume um papel mais relevante do que a alocação estratégica da água (EMPINOTTI; WARNER, 2012).

Por outro lado, tais discussões evidenciaram como o método da pegada hídrica está calcado em conceitos da economia neoclássica e guiado por princípios funcionalistas que assumem que o uso eficiente da tecnologia, combinado às regras de mercado, seria suficiente para garantir a segurança hídrica de diferentes países (LOPEZ-GUNN; LLAMAS, 2008; EMPINOTTI; WARNER, 2012). Esta perspectiva pode também ser reconhecida nos argumentos utilizados por Hoekstra (2008b), quando ele assume que o setor produtivo se mostrou interessado em utilizar tal conceito, ao reconhecer que a má gestão da água leva ao aumento dos riscos de suas atividades, em função da redução da disponibilidade hídrica, por danificar sua imagem coorporativa e por levar o Estado a aumentar o seu controle regulador sobre as atividades industriais (HOEKSTRA, 2008b).

Nessa perspectiva, a questão dos recursos hídricos se traduziu para a linguagem de mercado e eficiência, evidenciando o interesse de certos setores da sociedade por esta alternativa com o objetivo de aumentar a eficiência dos processos produtivos, onde a conservação da água seria uma consequência de tais ações. Entretanto, ainda está por ser analisado o impacto da apropriação do método da pegada hídrica pelo setor produtivo e sobre as estruturas sociais e políticas localizadas tanto na escala global como local.

\section{Estudo de caso: o Projeto Water Future Partnership}

Das várias empresas desenvolvendo iniciativas com a pegada hídrica, foi escolhido o caso da SABMiller, empresa sul-africana, pioneira no mundo ao associar a sua imagem às ações referentes aos recursos hídricos como parte de suas práticas socioambientais. Além disso, seu impacto no setor de bebidas é considerável, uma vez que suas atividades estão presentes em 75 países distribuídos em todos os continentes e com expressiva presença na África. Atualmente, é uma das principais fabricantes de cerveja do mundo, com seus mercados localizados na América Latina (31\%), seguido pela África do Sul (23\%), Europa (17\%), América do Norte (14\%), África (13\%) e Ásia (2\%), assim como suas áreas de produção de cevada. Tal atividade industrial exerce uma forte pressão sobre a disponibilidade hídrica das suas regiões produtivas, uma vez que seu consumo no ano de 2009/10 foi equivalente a 72.200 milhões de litros de água (SABMILLER; WWF-UK et al., 2010).

A empresa começou a discutir estrategicamente a questão da água em 2007, quando fez uma análise sobre a disponibilidade da água a longo prazo em cada uma de suas plantas localizadas em várias partes do mundo, utilizando uma ferramenta que mapeia as bacias hidrográficas e sua disponibilidade hídrica por meio de banco de dados globais (SABMILLER; WWF-UK et al., 2010). Com isso, no ano de 2008, a SABMiller iniciou uma parceria com a WWF-UK, onde foi conduzido o estudo da pegada hídrica de seu processo produtivo em suas plantas localizadas na República Checa e na África do Sul, com o objetivo de identificar os riscos relacionados à disponibilidade hídrica na cadeia produtiva (SABMILLER; WWF-UK, 2009).

Foi no ano de 2009 que a SABMiller, juntamente com a WWF-UK e a GIZ (na época GTZ), criou a parceria chamada Water Future Partnership, com o objetivo de mostrar a importância do envolvimento e da liderança do setor privado no desenvolvimento de práticas que promovam o manejo sustentável dos recursos hídricos em conjunto com os atores locais presentes em bacias hidrográficas localizadas no Peru, Tanzânia, Ucrânia e África do Sul, onde o trabalho está sendo desenvolvido (SABMILLER; WWF-UK et al., 2011). Esta estratégia foi composta por três fases. A primeira fase consistiu em definir a pegada hídrica do processo produtivo da cerveja com o objetivo de identificar os fatores de risco e desenvolver um plano de ação em nível local e para o país onde o estudo foi conduzido. A segunda fase consistiu em mitigar os riscos identificados com relação à disponibilidade hídrica na região estudada por meio de parcerias com atores locais, como comunidades, 
produtores rurais e o Estado. Por fim, a terceira fase, ainda em andamento, consiste em aumentar as parcerias em outras escalas, para que as lições aprendidas sejam divulgadas e auxiliem na discussão e na elaboração de práticas de governança que garantam o acesso à água a todos os seus usuários e ao ecossistema (SABMILLER; WWF-UK et al., 2011).

Essa combinação trouxe ao estudo de caso a possibilidade de analisar o impacto de tais ações não só na imagem da empresa, mas também na forma como cada um dos atores se reposicionou na discussão e na proposição de práticas de governança e futuras políticas públicas nos diferentes países onde atuam. Dessa maneira, foi possível analisar como a água passou de insumo de produção para indicador de responsabilidade ambiental e, por fim, a instrumento de construção de práticas de governança ambiental, evidenciando a participação do setor privado nesse processo.

\section{Quando o setor privado se torna um parceiro: o reposicionamento da SABMiller, WWF e GIZ}

Como resultado da parceria no projeto Water Future Partnership, houve alterações no posicionamento dos atores envolvidos, com o objetivo de adequarem os seus interesses individuais na tentativa de influenciar seus parceiros e atingir suas próprias metas. Nesse contexto, a água foi entendida ao mesmo tempo de várias maneiras: 1) como insumo de produção, 2) como um recurso a ser conservado, e 3) como um recurso a ser distribuído de forma equitativa, seguindo os objetivos de cada parceiro envolvido na iniciativa. Essas três perspectivas foram unidas pelo entendimento de que a falta do acesso à água leva risco à produção industrial, à preservação ambiental e à promoção do desenvolvimento econômico local. A combinação dessas perspectivas levou tais organizações a caminharem em uma mesma direção, onde a conservação do recurso se tornou chave para todos os envolvidos, mas ao mesmo tempo levou ao comprometimento de alguns de seus princípios.

Esta aliança, juntamente com o discurso criado para que ela ocorresse, reposicionou principalmente o setor privado nos espaços de negociação no contexto dos recursos hídricos. Por um lado, a empresa SAB-
Miller se beneficiou de sua aproximação da WWF e GIZ, organizações reconhecidas por seu compromisso com as questões de preservação ambiental e redução da pobreza, e dessa forma tentou passar a mensagem de seu comprometimento com tais causas também. Além disso, a empresa incorporou a gestão da água em sua imagem corporativa, ao considerar o uso eficiente e racional da água como o segundo principal compromisso da empresa e ao definir como meta diminuir em $25 \%$ a quantidade de água utilizada na sua produção até 2015 (SABMILLER; WWF-UK et al., 2010). A empresa também abriu o diálogo com os outros atores sociais envolvidos. Em primeiro lugar, ela identificou que a problemática da água e seu uso devem ser assumidos pelos vários usuários e atores da bacia e, por isso, iniciou um trabalho de mapeamento do uso da água por meio do método da pegada hídrica. Dessa forma, a empresa propôs iniciativas com o objetivo de motivar não apenas a si mesma, mas também aos outros usuários de água a desenvolverem práticas que levem à redução do uso e à conservação do ambiente, para que a bacia mantenha a sua disponibilidade hídrica.

Por meio desta estratégia, a empresa dividiu a sua responsabilidade sobre o impacto de suas práticas produtivas nos recursos hídricos com os outros usuários, diluindo dessa maneira sua reponsabilidade sobre a conservação do recurso. Tal movimento é sutil, mas ao mesmo tempo extremamente estratégico, uma vez que as atenções são agora polarizadas entre os vários usuários da água na bacia, assim como a sua responsabilidade com o uso eficiente do recurso.

Por outro lado, a aproximação da WWF com a SABMiller refletiu a mudança de postura desta ONG ambientalista com relação ao setor privado. Anteriormente, as ações da WWF se concentravam fortemente nas parcerias com os Estados de diferentes países, com o objetivo de promover programas de governo que levassem à conservação da natureza. Sua estratégia era a de ter acesso a fundos nacionais e internacionais que levassem à elaboração e à aprovação de arcabouços institucionais, que contribuiriam para alcançar o objetivo da preservação do meio ambiente em primeiro lugar. Dessa forma, a identidade da ONG foi construída ao redor da imagem da conservação e proteção do ambiente contra o mau uso e destruição muitas vezes causada por atividades produtivas. Com isso, o papel da WWF era criar dispositivos que 
protegessem a natureza contra seus degradadores, onde o setor privado e suas práticas de produção eram um dos principais responsáveis. A partir de 2006, a WWF inicia parcerias com empresas do setor privado com o objetivo de influenciar e diminuir o impacto dos processos produtivos sobre o ambiente, desta forma aumentando seu leque de ações e transformando o setor produtivo de ator antagônico aos seus objetivos em parceiro na preservação da natureza (MASON; O'MAHONY, 2008; PEGRAM; ORR et al., 2009).

Com isso, ao se aproximar do setor produtivo, a WWF se tornou um interlocutor do processo de realocação deste setor nas estruturas de governança da água, ao atrair a atenção da indústria para a questão de risco que a falta de água oferece às práticas produtivas e ao mesmo tempo oferecer ferramentas de gestão - como a pegada hídrica - que auxiliam na identificação dos pontos a serem trabalhados. Pelo fato de a pegada hídrica possibilitar o entendimento do uso da água além das fronteiras físicas da empresa, ao considerar todo o processo produtivo, a iniciativa da WWF tinha como objetivo demonstrar que a solução para os problemas referentes à qualidade de água e seu acesso é responsabilidade de todos na bacia e assim abriria um espaço de diálogo entre os usuários de água e as populações presentes na bacia (PEGRAM; ORR et al., 2009; ORR; CARTWRIGHT, 2010). Dessa forma, a WWF começou a ser reconhecida, devido às suas ações, como parceira do setor produtivo e assim agregando a sua identidade a atores até então reconhecidos pela sua falta de compromisso e respeito às questões ambientais.

Por fim, a GIZ contribuiu no reposicionamento da SABMiller, ao se tornar o parceiro responsável em levar tal discussão para as esferas internacionais, além de servir como interlocutor com governos locais. Antes concentrando suas parcerias principalmente com o Estado e as organizações não governamentais, a GIZ, desde 2002, identificou que empresas privadas têm um papel crucial no desenvolvimento de regiões e países, uma vez que suas atividades influenciam não apenas o crescimento econômico, mas também o bem-estar das comunidades (GIZ, 2012a, 2012b). Nessa parceria, ela ofereceu o seu conhecimento e sua experiência em trabalhar com comunidades por meio de práticas participativas. Além disso, com o objetivo de assegurar acesso à água pela popula- ção da bacia, a GIZ aproveitou o seu conhecimento em trabalhar com governos, principalmente em países onde as instituições formais participativas e descentralizadas ainda não foram criadas, e ofereceu à empresa caminhos para influenciar na elaboração de políticas públicas que conciliem os interesses do setor privado e do Estado. Dessa forma, a GIZ continuou com a sua finalidade maior, que é a de influenciar o aparato institucional dos países, com o objetivo de fomentar a implantação de práticas que ela acredita serem as mais adequadas para combater a pobreza; entretanto, a maneira de colocar tais ideias em prática se alterou. Nesse contexto, a GIZ se posicionou como uma prestadora de serviços e vende, como uma de suas capacidades, o acesso a governos e arenas internacionais de negociação, dessa forma deixando de ser o principal ator de transformação institucional e se tornando interlocutor de mudanças, onde o setor privado assumiu um papel de destaque.

\section{Contribuindo na construção de novos espaços de negociação: a combinação entre novas parcerias e o uso da pegada hídrica}

As consequências da parceria desenvolvida entre a SABMiller, a WWF e a GIZ na reformulação do significado da água e o reposicionamento do setor privado nos espaços de discussão podem também ser entendidos como reflexos das alterações nas relações políticas e sociais do setor privado com relação às questões dos recursos hídricos. Até as décadas de 1960 e 1970, o setor privado era considerado como um agente de transformação da paisagem hídrica, ao utilizar tal recurso como insumo para a sua produção sem se responsabilizar pelo seu impacto nos ecossistemas, nas bacias e nas populações presentes nessas áreas (HART, 1997). Nesse período, as regras que controlavam emissões de poluição não existiam e o setor privado não considerava nas suas práticas produtivas o impacto de suas atividades na degradação do ambiente e na saúde das pessoas, levando em conta apenas oportunidades que se refletissem em ganhos de produção e de mercado. Com o surgimento das leis ambientais e políticas públicas, iniciou-se um processo de regulamentação e controle de níveis de poluição gerados pelas atividades econômicas, mas que ainda favorecia 
um modelo de desenvolvimento que identificava o crescimento econômico como alavanca de desenvolvimento (DRUMMOND; BARROS-PLATIAU, 2006). Nesse contexto, o setor privado desenvolveu um aparato de estratégias, que incluíam o lobby, e que tinham por objetivo influenciar e manipular a elaboração das políticas públicas e assim evitar a elaboração de legislações que pudessem aumentar o custo de produção e as responsabilidades das empresas com relação ao uso e impacto sobre os recursos naturais (PEGRAM; ORR et al., 2009).

A partir dos anos 1990, percebe-se a diminuição da influência central do Estado na tomada de decisão e as organizações da sociedade civil assumem um papel importante ao influenciar políticas públicas e ações do Estado (RADCLIFFE; WESTWOOD, 1993; PRICE, 1994; RADCLIFFE, 2001; JACOBI; SINISGALLI, 2009). Ao mesmo tempo, o setor privado se privilegia de um Estado menos intervencionista e que assume o papel de regulador da atividade produtiva (GORE, 2000).

Com a contração da influência do Estado nas atividades privadas e da sua transformação em gerenciador e regulador, investidores e consumidores começaram a influenciar as ações do setor privado, ao questionarem as práticas de produção, principalmente com relação ao seu impacto no ambiente e nas populações (CONROY, 2007; MASON; O'MAHONY, 2008). Em resposta, as empresas iniciaram um diálogo com a sociedade por meio de seus relatórios de responsabilidade socioambiental, que muitas vezes se limitam a relatar o impacto de suas ações sobre o ambiente. Entretanto, o canal de diálogo ocorre apenas em uma direção, onde as empresas relatam suas atividades e iniciativas, mas não consideram a opinião dos consumidores e comunidades locais nos processos de tomada de decisão internos das empresas (HART, 1997; MASON; O’MAHONY, 2008; HEUER, 2010).

Na análise do caso da SABMiller e de sua iniciativa com a WWF e a GIZ, percebemos uma nova dinâmica de integração entre o setor privado, organizações da sociedade civil e agências multilaterais, o que proporcionou, ainda de forma muito tímida, a influência de organizações ambientalistas e agências de desenvolvimento em práticas de gestão nas empresas. Nesse caso, as empresas se transformaram em um canal de ação na implementação de novas práticas para trabalhar com a questão dos recursos hídricos. Com isso, a negociação e o diálogo se tornaram estratégias-chave na mudança de posicionamento do setor privado, uma vez que as sugestões de práticas de uso da água integradas na bacia devem ser estrategicamente apresentadas, a ponto de influenciar as ações de outros usuários e do Estado.

Ao se posicionar como liderança na discussão sobre recursos hídricos nas áreas onde as fábricas da SABMiller estão localizadas, a empresa ocupou novos espaços presentes nas esferas de negociação, com o objetivo de garantir seus interesses e influenciar o processo de tomada de decisão de uma forma proativa. Tal mudança não é trivial, pois oferece à SABMiller um outro caminho para influenciar políticas públicas, além das práticas de lobby já utilizadas. Por outro lado, mesmo de forma não intencional, ao se posicionar como liderança nas discussões referentes à gestão eficiente dos recursos hídricos, a empresa se viu obrigada a expor os seus planos de ação aos parceiros da bacia e assim criou oportunidades para que a sociedade pudesse exercer o monitoramento de tais ações e ao mesmo tempo cobrar os compromissos assumidos.

Por outro lado, o uso da pegada hídrica proporcionou a criação de um diálogo, onde o ponto agregador foi a visualização dos fluxos de água sendo utilizados pelas diferentes atividades ocorrendo nas bacias e o impacto de sua alocação no ambiente e na população. Ao proporcionar argumentos que possam levar a uma discussão coletiva, o método também reconhece as características físicas da água, como a sua mobilidade e o fato de ações que ocorrem em determinada parte da bacia exercerem impacto em toda uma região, além de salientar a importância de ações coletivas para levar à melhoria da qualidade e disponibilidade de tal recurso, uma vez que ações isoladas não atingirão o resultado esperado (SAVENIJE, 2001).

\section{O que esperar do entendimento da água como indicador de responsabilidade socioambiental}

Como apresentado e discutido nesse artigo, a aliança entre a empresa SABMiller, a organização ambiental WWF e a agência de desenvolvimento GIZ proporcionou a possibilidade de construção de um novo espaço para exercer a governança da água. Ao redefinir 
a importância da água no processo produtivo, houve o reposicionamento de novos atores nos espaços de governança, assim como a possibilidade de surgimento de novos arranjos institucionais onde o setor privado seria um agente-chave na negociação de práticas referentes à utilização e à conservação dos recursos hídricos.

Entretanto, esta discussão também possibilitou o surgimento de uma série de questões referentes ao comprometimento do setor industrial com a questão da conservação dos recursos hídricos, as consequências para a sua imagem devido à aproximação de ONGs ambientalistas e agências de desenvolvimento com o setor privado e, por fim, a eficiência e suficiência do método da pegada hídrica na promoção de práticas coletivas que garantam a disponibilidade hídrica das regiões.

Com relação ao setor industrial, é importante aprofundar o entendimento sobre a maneira como a utilização da pegada hídrica contribuiu ou não para o desenvolvimento de iniciativas com foco no uso eficiente da água e na criação de espaços políticos que, futuramente, possam influenciar na elaboração de políticas públicas. Estudos têm mostrado que empresas se interessam pelo método da pegada hídrica ao identificarem-no como uma oportunidade de valoração de seus produtos no mercado, desta maneira transformando uma iniciativa que visa a uma questão ambiental em um ganho de mercado e possivelmente de aumento de lucros e melhora na sua imagem coorporativa (EMPINOTTI, 2012). O desenvolvimento de iniciativas localizadas por meio de parcerias com os atores locais vem assumindo muito mais um caráter de marketing das empresas do que a promoção de discussões sobre comprometimentos que, porventura, possam ser assumidos por elas. Dessa maneira, é importante que iniciativas como a da SABMiller sejam analisadas mais profundamente, com o objetivo de verificar se elas continuarão a ocorrer, mesmo que não haja ganho econômico para a empresa, ou como as empresas se posicionarão em discussões relacionadas à definição de indicadores de eficiência do uso da água.

Outra questão a ser aprofundada é com relação à mudança do papel de organizações ambientais e agências de desenvolvimento, no momento que iniciaram parcerias com o setor privado. Até que ponto estas iniciativas estão respondendo às expectativas dessas organizações? Seria possível identificar a contribuição delas no comprometimento do setor privado com a questão da conservação dos recursos hídricos ou na garantia da disponibilidade hídrica para toda a população? Nesse contexto, o setor privado está realmente assumindo um papel de liderança ao defender as causas ambientais e sociais como estas organizações propõem?

Por outro lado, seria também interessante analisar qual o impacto da aproximação dessas organizações com o setor privado sobre a sua imagem e identidade. Como a sociedade responde a essa aproximação e qual seria o impacto sobre a sua imagem de defensores de causas consideradas louváveis para a sociedade?

Por fim, um outro aspecto a ser discutido é a capacidade do método da pegada hídrica em contribuir na criação de novas práticas de governança da água e no entendimento do recurso água. Nesse artigo, se observou que a parceria discutida gerou propostas de ação a serem desenvolvidas de forma coletiva nas bacias hidrográficas, que a maneira de se discutir a questão da água foi alterada, uma vez que a responsabilidade em cuidar da água foi distribuída entre todas as atividades ocorrendo nessas bacias. Até o momento, a relação entre a governança da água e a pegada hídrica não foi ainda analisada em profundidade, uma vez que a maioria das discussões sobre o método se concentrou no método em si (PFISTER; HELLWEG, 2009; PFISTER; KOEHLER et al., 2009; RIDOUTT; PFISTER, 2010) e nas consequências de sua aplicação como referência na definição de regras de comércio exterior e na priorização da produção agrícola dos países, de acordo com a pegada hídrica de suas culturas (CARMO; OJIMA et al., 2007; WARNER; JOHNSON, 2007; WICHELNS, 2010; WARNER; SEBASTIAN et al., 2013).

Sem dúvida, o fato de o método da pegada hídrica não enfocar apenas na geração de valores, mas sim promover uma análise contextualizada sobre o significado desses dados nas bacias onde as atividades econômicas estão ocorrendo, traz uma inovação que outros métodos, como a Análise de Ciclo de Vida, não oferecem. Entretanto, é necessário que, em estudos futuros, sejam analisados aspectos como a possibilidade da concretização do potencial da pegada hídrica, de que maneira impactou a forma como os usuários da água entendem esse recurso, o impacto sobre as suas estratégias políti- 
cas, assim como a geração de novas políticas públicas embasadas nos resultados dessas iniciativas.

Dessa forma, a pegada hídrica foi apropriada por segmentos do setor produtivo como um indicador de responsabilidade socioambiental, com o objetivo inicial de valorizar o produto no mercado por servir como uma prova do seu compromisso com o uso eficiente dos recursos hídricos. Essa valorização da eficiência no uso dos recursos hídricos promoveu a criação de novas relações não só sobre o entendimento da água na cadeia produtiva, mas também no surgimento de parcerias até então inexistentes. Os desdobramentos desse novo entendimento e seu impacto sobre as estratégias de ação, tanto do setor privado como das organizações da sociedade civil, contribuirão para a compreensão de como a água pode se tornar um canal de influência na construção de práticas de governança que, futuramente, possam regular o seu uso e o seu acesso.

\section{Referências}

ABERS, R. N. Organizing for Governance: Building Collaboration in Brazilian River Basins. World Development, v. 35, n. 8, p. 1450-1463, 2007.

ALLAN, A. J. Virtual Water: a strategic resource, global solutions to regional deficits. Groundwater, v. 36, n. 4, p. 545-546, 1998.

ALLAN, J. A. The middle east water question. Hydropolitics and the global economy. London: I. B. Tauris, 2001.

. Virtual Water - the water, food and trade nexus. Useful concept or misleading metaphor? Water International, v. 28, n. 1, p. 4-10, 2003.

BAKKER, K. An uncooperative commodity: privatizing water in England and Wales. Oxford: Oxford University Press, 2004.

BANK, W. World Bank Development Report 1992. Development and the Environment. New York: World Bank, 1992. p. 308.

BOELENS, R.; VOS, J. The danger of naturalizing water policy concepts: water productivity and efficiency discourses from field irrigation to virtual water trade. Agriculture Water Management, v. 108, p. 16-26, 2012.

BRAGA, B.; STRAUSS, C.; PAIVA, F. Water Charges: Paying for the Commons in Brazil. In: BISWAS, A.; TORTAJADA, C. (Ed.). Water Pricing and Public-Private Partnership. New York: Routledge, 2005.

BRANNSTROM, C. Decentralizing Water Resources Management in Brazil. European Journal of Development Research, v. 16, n. 1, p. 214-234, 2004.

BRAUN, B. Environmental Issues: inventive life. Progress in Human Geography, v. 32, n. 5, p. 667-679, 2008.
BRYANT, R. L. A Political Ecology for Developing Countries? Progress and Paradox in the Evolution of the Research Field. Zeitschrift fur Wirtschaftsgeographie, v. 34, n. 3-4, p. 148-157, 1999.

; BAILEY, S. Third World Political Ecology. London: Routledge, 1997. p. 237.

BUDDS, J. Power, Nature and Neoliberalism: The Political Ecology of Water in Chile. Singapore Journal of Tropical geography, v. 25, n. 3, p. 322-342, 2004.

BUSTAMANTE, R. The water war: resistance against privatization of water in Cochabamba, Bolivia. REGA, v. 1, n. 1, p. 37-46, 2004.

CARMO, R. L. D. et al. Água virtual, escassez e gestão: o Brasil como grande "exportador" de água. Ambiente e Sociedade, v. 10, n. 2, p. 83-96, 2007.

CASTREE, N. The nature of produced nature: materiality and knowledge construction in Marxism. Antipode, v. 27, p. 13-48, 1995.

Environmental Issues: relational ontologies and hybrid politics. Progress in Human Geography, v. 27, p. 203211, 2003.

CONROY, M. Branded! How the certification revolution is transforming global corporations. Gabriola Island: New Society Publishers, 2007.

DEWALT, B. R. The Political Ecology of Population Increase and Malnutrition in Southern Honduras. In: GOLDMAN, A.; LEATHERMAN, T. (Ed.). Building a New Biocultural Synthesis. University of Michigan, 1998. p. 295-316. 
EMPINOTTI, V. L.; JACOBI, P. R. Novas práticas de governança da água? O uso da pegada hídrica e a transformação...

DRUMMOND, J.; BARROS-PLATIAU, A. F. Brazilian Environmental Laws and Policies, 1934-2002: A Critical Overview. Law and Policy, v. 28, n. 1, p. 83-108, 2006.

EMPINOTTI, V. L. Re-framing Participation: the Political ecology of Water Management in the Lower São Francisco River Basin - Brazil. 2007. 297 f. (Ph.D). Geography, University of Colorado, Boulder, 2007.

O setor privado e a Pegada Hídrica: risco, oportunidade e vulnerabilidade. In: ; JACOBI, P. R. (Ed.). Pegada Hídrica: inovação, corresponsabilização e os desafios de sua aplicação. São Paulo: Annablume, 2012.

; WARNER, J. Água Virtual e Pegada Hídrica: as contribuições e desafios que estes conceitos trouxeram à maneira como discutimos os recursos hídricos. In: EMPINOTTI, V.; JACOBI, P. R. (Ed.). Pegada Hídrica: inovação, corresponsabilização e os desafios de sua aplicação. São Paulo: Annablume, 2012.

FÉRES, J.; REYNAUD, A. Assessing the Impact of Environmental Regulation on Industrial Water Use: Evidence from Brazil. Land Economics, v. 81, n. 3, p. 396-411, 2005.

et al. Demanda por água e custo de controle da poluição hídrica nas indústrias da bacia do rio Paraíba do Sul. Rio de Janeiro: IPEA, 2005.

FINE, B. Neither the Washington nor the Post-Washington consensus: An Introduction. In: FINE, B.; LAPAVITSAS, C. et al (Ed.). Development Policy in the Twenty-First Century. London: Routledge, 2001.

GERBENS-LEENES, P. M.; HOEKSTRA, A. Y. Business Water Footprint Accounting: A Tool to Assess how Production of Goods and Services Impacts on Freshwater Resources WorldWide. Delft: UNESCO-IHE, 2008. p. 40.

GIZ. Cooperation with the private sector. 2012a. Acesso em: 28/03/2012.

28/03/20012

GTZ - Corporate Identity. 2012b. Acesso em:

GOLDMAN, M. Imperial Nature: the World Bank struggles for social justice in the age of globalization. New Haven: Yale University Press, 2005.360

GORE, C. The Rise and Fall of the Washington Consensus as a Paradigm for developing Countries. World Development, v. 28, n. 5, p. 789-804, 2000.

HART, S. Beyond Greening: Strategies for a Sustainable World. Havard Business Review, v. 75, n. 1, p. 66-76, 1997.
HARVEY, D. Justice, Nature, and the Geography of Difference. Cambridge: Blackwell Publishers, 1996.

HEUER, M. Defining Stewardship: Towards an Organizational Culture of Sustainability. The Journal of Corporate Citizenship, v. 40 , p. $31-40,2010$.

HOEKSTRA, A. Y. Virtual Water Trade. In: International Expert Meeting on Virtual Water Trade, 2002. Delft: UNESCO - IHE, 2002.

Water Neutral: reducing and offsetting the impacts of water footprints. Delft: UNESCO - IHE, March 2008. p. 39. 2008a.

Business Water Footprint Accounting: A tool to access how production of goods and services impacts on freshwater resources worldwide. Delft: UNESCO - IHE, March 2008, p. 43. 2008b.

; CHAPAGAIN, A. K. Globalization of Water: Sharing the Planet's Freshwater Resources. Oxford: Blackwell Publishing, 2008.

; HUNG, P. Q. Globalization of water resources: international virtual water flows in relation to crop trade. Global Environmental Change, v. 15, n. 1, p. 45-56, 2005.

et al. The Water Footprint Assessment Manual: Setting the Global Standard. London: Earthscan, 2011. p. 203.

IORIS, A. The troubled water of Brazil: nature commodification and social exclusion. Capitalism Nature Socialism, v. 18, n. 1, p. 28-50, 2007.

JACOBI, P. R. A gestão participativa da bacias hidrográficas no Brasil e os desafios do fortalecimento de espaços colegiados. In: NOBRE, M.; SCHATTAN, V. (Ed.). Participação e deliberação: Teoria democrática e experiências institucionais no Brasil contemporâneo. São Paulo: Editora 34, 2004. p. 270-289.

. Participação da Gestão Ambiental no Brasil: os Comitês de Bacias Hidrográficas e o desafio do fortalecimento de espaços públicos colegiados. In: ALIMONDA, H. (Ed.). Los Tormentos de la Materia. Buenos Aires: CLACSO Libros, 2006. p. 169-194.

. Governança da água no Brasil. In: RIBEIRO, W. (Ed.). Governança da água no Brasil: uma visão interdisciplinar. São Paulo: Annablume, 2009. p. 35-60.

; SINISGALLI, P. Governança da água na América Latina e Europa: atores sociais, conflitos e territorialidade. São Paulo: Annablume, 2009. 
LEE, T. Changes in water resources administration in Latin America. Natural Resources Forum, v. 19, n. 3, p. 243-248, 1995.

LEONEL, M. A morte social dos rios. São Paulo: FAPESP, 1998. p. 263.

LIPSCHUTZ, R. D. The Nature of Sovereignty and Sovereignty of Nature: Problematizing the Boundaries between Self, Society, State, and System. In: LITFIN, K. (Ed.). The Greening of Sovereignty in World Politics. Cambridge: The MIT Press, 1998. p. 109-140.

LOPEZ-GUNN, E.; LLAMAS, M. R. Re-thinking water scarcity: can science and technology solve the global water crisis? Natural Resources Forum, v. 32, n. 3, p. 228-238, 2008.

LOTFUS, A. Rethinking Political Ecologies of Water. Third World Quarterly, v. 30, n. 5, p. 953-968, 2009.

MASON, M.; O'MAHONY, J. Post-traditional corporate governance. The Journal of Corporate Citizenship, v. 31, p. 31-44, 2008.

NATIONS, T. U. The United Nations World Water development Report 3: Water in a Changing World. London: UNESCO e Earthscan, 2009. p. 313.

ORR, S.; CARTWRIGHT, A. Water scarcity risk: experience of the private sector. In: MARTINEZ-CORTINA, L.; GARRIDO, A. et al. (Ed.). Rethinking water and food security. London: CRC Press, 2010. p. 181-189.

PEET, R.; WATTS, M. Liberation Ecology. In: PEET, R.; WATTS, M. (Ed.). Liberation Ecologies: environment, development, social movements. London: Routledge, 1996. p. 1-45.

PEGRAM, G.; ORR, S.; WILLIAMS, C. Investigation shared risk in water: corporate engagement with the public policy process. London: WWF-UK and HSBC, 2009.

PERREAULT, T. State Reestructuring and the Scale of Politics of Rural Water in Bolivia. Environment and Planning A, v. 37 , n. 2, p. 263-284, 2005.

PETRELLA, R. O Manifesto da Água: argumentos para um contrato mundial. Petrópolis: Vozes, 2002.

PFISTER, S.; HELLWEG, S. The water "shoesize" vs. footprint of bioenergy. Proceedings of the National Academy of Sciences of the United States of America, v. 106, n. 35, p. E93-E94, 2009.

; KOEHLER, A.; HELLWEG, S. Assessing the Environmental Impacts of Freshwater Consumption in LCA. Environmental Sciency Technology, v. 43, p. 4098-4104, 2009.
PRICE, M. Ecopolitics and Environmental Nongovernmental Organizations in Latin America. Geographical Review, v. 84, n. 1, p.42-58, 1994.

PRUDHAM, S. Taming Trees: Capital, Science, and Nature in Pacific Slope Tree Improvement. Annals of the Association of American Geographers, v. 93, n. 3, p. 636-656, 2003.

RADCLIFFE, S. Development, the State and Transnational Political Connections: State and Subject Firmations in Latin America. Global Network: A Journal of Transnational Affairs, v. 1, n. 1, p. 19-36, 2001.

; WESTWOOD, S. Viva: Women and Popular Protest in Latin America. London: Routledge, 1993.

REES, W. E. Ecological footprints and appropriated carrying capacity: what urban economics leaves out. Environment and Urbanization, v. 4, n. 2, p. 121-130, 1992.

RIBEIRO, W. C. Geografia Política da Água. São Paulo: Annablume, 2008. p. 162.

RIDOUTT, B. G.; PFISTER, S. A revised approach to water footprint to make transparent the impacts of consumption and production on global freshwater scarcity. Global Environmental Change, v. 20, p. 113-120, 2010.

ROTH, D.; WARNER, J. Virtual water: Virtuous impact? The unsteady state of virtual water. Agriculture and Human Values, v. 25, p. 257-270, 2008.

SABMILLER; UK, W. Water Footprint: identifying and addressing water risks in the value chain. 2009.

; WWF-UK; GIZ. Water Futures: addressing shared water challenges through collective action. 2011.

; GTZ. Water Futures: working together for a secure water future. 2010. p. 36.

SAVENIJE, H. H. G. Why water is not an ordinary economic good. Delft: IHE, 2001. p. 19.

SELIGSON, M. A.; PASSÉ-SMITH, J. T. Development and underdevelopment: the political economy of global inequality. Boulder: Lynne Rienner Publishers, 1998. p. 468.

SIKKINK, K. Development Ideas in Latin America: Paradigm shift and the Economic Commission for Latin America In: COOPER, F.; PACKARD, R. (Ed.). International Development and the Social Sciences: Essays on the History and Politics of Knowledge. Berkeley: University of California Press, 1997. p. 228-259.

SWYNGEDOUW, E. Power, nature, and the city. The conquest of water and the political ecology of urbanization in Guayaquil, 
Ecuador: 1880 - 1990. Environment and Planning A, v. 29, p. 311-332, 1997.

Modernity and hybridity: nature, regeneracionism, and the production of the Spanish waterscape, 1890-1930. Annals of the Association of American Geographers, v. 89, p.443-465, 1999.

Social Power and the Urbanization of Water: flows of power. Oxford: Oxford University Press, 2004. p. 209.

. Metabolic urbanization: the making of cyborg cities. In: HEYNEN, N.; KAIKA, M. et al. (Ed.). In the Nature of Cities: urban political ecology and the politics of urban metabolism. London: Routledge, 2006. p. 21-40.

VALLEJO, J. R.; ROGERS, P. Virtual water flows and trade liberalization. Water Science and Technology, v. 49, n. 7, p. 25-32, 2004.

WARNER, J.; JOHNSON, C. Virtual Water - Real People: Useful Concept or Prescriptive Tool? International Water Resources Association, v. 32, n. 1, p. 63-77, 2007.
; SEBASTIAN, A.; EMPINOTTI, V. Claiming (back) the land: The geopolitics of Egyptian and South African land and water grabs. In: ALLAN, T.; KEULERTZ, M. et al. (Ed.). Handbook of Land and Water Grabs in Africa. London: Routledge, 2013.

WESCOAT, J.; WHITE, G. Water for Life: Water Management and Environmental Policy. Cambridge: Cambridge University Press, 2003. p. 322.

WICHELNS, D. Virtual Water: A Helpful Perspective, but not a Sufficient Policy Criterion. Water Resource Management, v. 24, p. 2203-2219, 2010.

ZIMMERER, K. S. The reworking of conservation geographies: non-equilibrium landscapes and nature-society hybrids. Annals of the Association of American Geographers, v. 90, p. 356-369, 2000.

Recebido em 2 de julho de 2012. Aceito em 20 de março de 2013. Publicado em junho de 2013. 